\title{
Alcohol consumers' attention to warning labels and brand information on alcohol packaging: Findings from cross-sectional and experimental studies
}

Inge Kersbergen ${ }^{*}$ and Matt Field

\begin{abstract}
Background: Alcohol warning labels have a limited effect on drinking behavior, potentially because people devote minimal attention to them. We report findings from two studies in which we measured the extent to which alcohol consumers attend to warning labels on alcohol packaging, and aimed to identify if increased attention to warning labels is associated with motivation to change drinking behavior.

Methods: Study $1(N=60)$ was an exploratory cross-sectional study in which we used eye-tracking to measure visual attention to brand and health information on alcohol and soda containers. In study $2(N=120)$ we manipulated motivation to reduce drinking using an alcohol brief intervention (vs control intervention) and measured heavy drinkers' attention to branding and warning labels with the same eye-tracking paradigm as in study 1 . Then, in a separate task we experimentally manipulated attention by drawing a brightly colored border around health (or brand) information before measuring participants' self-reported drinking intentions for the subsequent week.
\end{abstract}

Results: Study 1 showed that participants paid minimal attention to warning labels (7\% of viewing time). Participants who were motivated to reduce drinking paid less attention to alcohol branding and alcohol warning labels. Results from study 2 showed that the alcohol brief intervention decreased attention to branding compared to the control condition, but it did not affect attention to warning labels. Furthermore, the experimental manipulation of attention to health or brand information did not influence drinking intentions for the subsequent week.

Conclusions: Alcohol consumers allocate minimal attention to warning labels on alcohol packaging and even if their attention is directed to these warning labels, this has no impact on their drinking intentions. The lack of attention to warning labels, even among people who actively want to cut down, suggests that there is room for improvement in the content of health warnings on alcohol packaging.

Keywords: Alcohol, Alcohol packaging, Eye-tracking, Health warnings, Motivation to reduce drinking, Visual attention

\footnotetext{
* Correspondence: iker@liv.ac.uk

Department of Psychological Sciences, University of Liverpool, UK and the

UK Centre for Tobacco and Alcohol Studies (UKCTAS), Liverpool L69 7ZA, UK
} 


\section{Background}

In March 2011, alcohol beverage companies in the UK pledged to put warning labels on $80 \%$ of alcoholic drink containers as part of the public health responsibility deal [1]. These labels contain 1) the alcohol content (UK units), 2) the daily guidelines for maximum alcohol consumption, 3) a pregnancy warning, 4) a link to drinkaware.co.uk, the website of an industry sponsored charity (optional), and 5) a responsibility statement (optional; [2]). ${ }^{1}$ Warning labels have a limited effect on drinking behaviour. Narrative reviews of the evidence on alcohol health warnings demonstrated that public awareness of the warning label typically increases after implementation, but this does not translate to increased alcoholrelated risk perceptions or reduced alcohol consumption [3-5]. Similarly, a systematic review showed that information-based policies (such as warning labelling) are generally ineffective [6], and researchers have argued that the pledges included in the responsibility deal are therefore unlikely to affect behaviour [7].

It is possible that warning labels have a limited effect on drinking behaviour because people pay little attention to them. Indeed, participants spent on average $7 \%$ of total viewing time looking at warning messages in alcohol advertisements [8]. However, there are likely to be individual differences in the amount of attention paid to health warning information, which may be important. Tobacco and food literature shows that consumption habits [9, 10] and goals [11] affect attention towards warning labels. In turn, attention to warning labels might also influence behaviour. For example, bar visitors drank less alcohol if their attention had been drawn to warning labels [12]. Similarly, nutrition labels had a stronger influence on product choice when they were attended to longer [13]. This raises the possibility that if warning labels on alcohol packaging are sufficiently 'attention grabbing, their impact on alcohol consumption at the population level could be substantial.

Unfortunately, nothing is known about the extent to which alcohol consumers attend to warning labels, how much their attention is related to individual differences in drinking behaviour and motivation to change it, and whether beneficial behaviour change is a likely consequence of increasing attention to warning labels on packaging. The purpose of the studies reported here was to investigate how much attention is paid to warning labels and branding on alcohol beverage containers, and how individual differences in this are associated with individual differences in drinking behaviour and motivation to change it. In both studies, we measured participants' eye movements towards brand information and warning labels whilst they viewed alcohol beverage containers. Study 1 was an exploratory study that gathered descriptive information about how much attention alcohol consumers pay to health information and investigated correlations between attention and drinking habits. We hypothesized that heightened motivation to reduce drinking would be associated with increased attention to health warnings. In study 2 , we experimentally manipulated motivation to reduce drinking and attention to health warnings in order to investigate the causal relationships between them.

\section{Study 1 \\ Method \\ Participants}

Sixty participants (63\% female) were recruited via online advertisements circulated among students and staff of the University of Liverpool. The sample size was based on previous research on attention to warning labels in alcohol print advertisements [8]. Participants were eligible to take part if they were aged over 18 and did not wear glasses. The majority were alcohol consumers $(n=$ 58). Their mean age was $21.27(\mathrm{SD}=3.61)$. They had a mean Alcohol Use Disorders Identification Test (AUDIT) score of $10.67(\mathrm{SD}=6.54)$ and drank on average $32.12(\mathrm{SD}=29.15)$ UK units in the 14 days prior to the experiment (1 UK unit $=8 \mathrm{~g}$ of alcohol). The study received ethical approval from the University of Liverpool Research Ethics Committee.

\section{Materials}

Stimuli We photographed 50 beverage containers (bottles or cans) of various brands and types of alcoholic and non-alcoholic beverages that included health/warning labels (i.e., UK warning label on alcohol containers, nutrition information on soda containers). We photographed 25 alcohol containers (11 bottles/cans of beer, 6 cans of pre-mixed cocktails, 3 bottles/cans of cider, 3 bottles of alcopops and 2 bottles of wine) and 25 soda containers (23 bottles/cans of carbonated soft drinks and 2 bottles of fruit juice). We took four photographs of each container, two of the front and two of the back. One front and one back picture depicted the whole bottle or can, whereas a different picture depicted a closeup of the front label and the back label. The location of the alcohol warning labels varied between the containers. All aspects of the warning labels were visible and readable in the close-up during the viewing task. Most warning labels were in compliance with the guidelines specified in the responsibility deal and included the alcohol content, the daily guidelines for alcohol consumption, a pregnancy warning, an optional link to drinkaware.co.uk, and an optional responsibility statement. Two labels also included nutrition information. Three labels did not meet the minimum requirements: they did not include the daily recommended guidelines, and two 
of these also did not include a pregnancy warning. Nevertheless, we included these labels in our analyses as research has shown that $22.4 \%$ of alcohol warning labels did not comply with the responsibility deal guidelines [14]. Therefore, our stimuli were representative of the warning labels used in the UK.

Eye-tracker task Participants were asked to view images of beverage containers (viewing phase) before their memory for the containers was tested (recognition phase; the latter was included to encourage participants to pay close attention during the viewing phase). In the viewing phase participants viewed 40 containers from the stimulus set $(20$ alcohol, 20 soda). They were instructed to use the arrow keys to manipulate the display of the containers. The left and right arrow keys were used to alternate between front and back. The up arrow was used to zoom in on the label and the down arrow was used to zoom out. Each container was presented for $15 \mathrm{~s}$ and participants were free to manipulate the presentation of the container in any way they liked. Whether the 'zoomed out' front or back of the container was presented first was randomized on a trial-by-trial basis. To ensure that all participants had the same starting position at image onset, participants were instructed to look at a fixation cross that was presented for $1 \mathrm{~s}$ before the trial started. Participants' eye movements were measured using an ASL Eye-Trac D6 (Applied Science Laboratories, Bedford, MA) at a sampling rate of $120 \mathrm{~Hz}$

In the recognition phase, participants were shown a second set of 20 images (10 new and 10 of the 40 that had been presented during the viewing phase) and were asked to indicate whether or not each image had been present in the previous set by pressing a "yes" or "no" button. Recognition accuracy was defined as the percentage of correct trials. Participants correctly answered $M=95.83 \%(\mathrm{SD}=5.38)$ of the recognition trials.

\section{Questionnaires}

Alcohol use disorders identification test (AUDIT [15]) The AUDIT is a 10-item screening instrument assessing hazardous patterns of alcohol use and dependence symptoms. An example of an item is "How often do you have six or more drinks on one occasion?". Each item is answered in a multiple choice format (e.g. "never", "less than monthly", "monthly", "weekly" or "daily or almost daily"). Scores range between 0 and 40 . AUDIT scores of 8 or higher are indicative of hazardous or harmful drinking patterns [15]. The AUDIT has good test-retest reliability, internal reliability and construct validity [16]. 14-day retrospective timeline follow-back diary (TLFB [17]) Participants were required to sum up for every day of the past two weeks, how many alcoholic drinks they had consumed in UK units. The TLFB has high test-retest reliability and good concurrent validity $[17,18]$.

Temptation Restraint Inventory - Restrain subscale (TRI [19]) The TRI restraint subscale is a 3-item scale answered on a 9-point Likert scale with anchors "never" and "always". An example of an item is "How often do you attempt to cut down the amount you drink?". Scores on the TRI restrain subscale range between 3 and 21 . The TRI has adequate internal reliability and concurrent validity [19].

Readiness to Change Questionnaire (RTCQ [20]) The RTCQ is a questionnaire with three subscales (Precontemplation, Contemplation, and Action). The subscales are 4-item scales answered on a 5-point Likert scale with anchors "strongly disagree" and "strongly agree". Examples of items are "I don't think I drink too much" (precontemplation subscale), "I enjoy my drinking, but sometimes I drink too much" (contemplation subscale), and "I am trying to drink less than I used to" (action subscale). Scores on each RTCQ subscale range between -8 and 8 . The RTCQ has good internal reliability and concurrent validity [20].

Contemplation ladder [21] The contemplation ladder is an 11-point scale on which participants are required to indicate their readiness to reduce their drinking (ranging from 0 "No thought of reducing how much I drink per occasion" to 10 "Taking action to reduce the number of drinks I have per occasion"). The contemplation ladder has good concurrent validity [21].

Dutch Eating Behaviour Questionnaire - Restraint subscale (DEBQ; [22]) Dietary restraint was measured with the DEBQ Restraint subscale. This is a 10-item scale answered in a multiple choice format ("not relevant", "never", "seldom", "sometimes", "often", "very often"). An example of an item is "Do you watch exactly what you eat?". Scores on the DEBQ Restraint subscale range between 10 and 50. The DEBQ Restraint subscale has high internal reliability and test-rest reliability [23] and good construct validity [24].

\section{Procedure}

After providing informed consent, participants completed the eye-tracker task. Then, they completed the questionnaire battery on a computer. A motivation to reduce drinking score was created by averaging the TRI restraint subscale, the RTCQ contemplation and action 
subscales and the contemplation ladder as these scales were strongly correlated $(r=.53-.80, p \mathrm{~s}<.001)$. Finally, participants were thanked and debriefed. Participants received study credits or a $£ 5$ shopping voucher.

\section{Data preparation and analysis}

On each container, Areas of Interest (AOIs) were created by assigning the warning label and any calorie information to the category Health; any brand information, such as the logo and any brand messages to the category Brand; and everything else (e.g., barcode, recycling logo, blank packaging material) to the category Rest. The relative size of each AOI was calculated by dividing the number of pixels in the area by the total number of pixels of the container. The complexity of each AOI was calculated by dividing the compressed file size by the uncompressed file size [25]. Brightness and contrast values for each AOI were obtained using GNU Imagine Manipulation Program 2.

The different containers varied considerably in their visual characteristics (see Table 1), and conventional multivariate statistics are unable to control for this within-stimulus variability. Therefore, we used multilevel modelling to analyse eye movements. Data were organised in three levels, with AOIs (Brand, Health, Rest; level 1) nested in individual containers (40 containers; level 2) nested in data from each individual participant (level 3). To eliminate noise due to inaccurate eye-tracking, trials in which participant spent less than $50 \%$ of the viewing time looking at the product (Health, Brand and Rest combined - the only stimuli on the screen) were excluded from the analyses $(12 \%)$. This percentage is similar to previous research on visual attention to tobacco warning labels, in which $8 \%$ [9] to $14 \%$ [26] of participants were excluded from analyses due to inaccurate tracking.

We created multilevel models to analyse the effect of stimulus characteristics and drinking habits on fixation time. AOI (brand, health, rest (reference category, dummy coded)), order of presentation, size, complexity, brightness, and contrast were level 1 predictors; picture type (alcohol, soda (reference category)) was a level 2 predictor; and motivation to reduce drinking, alcohol consumption, AUDIT scores and dietary restraint were level 3 predictors. The models included random intercepts for all three levels.

In Model 1, we included all level 1 and level 2 predictors and their first and second order interactions with AOI and picture type. Model 1 showed that stimulus characteristics significantly influenced attention to the different AOIs on alcohol and soda packaging. In Model 2, we included all level 3 predictors and their first and second order interactions with AOI and picture type. A chi-squared test showed that Model 2 was a significantly better fit than Model 1 $\left(\chi^{2}(24)=1015.93, p<.001\right)$, indicating that both participant characteristics and stimulus characteristics predicted fixation time.

\section{Results}

\section{Attention to branding and health warnings (Fig. 1)}

Over the $15 \mathrm{~s}$ viewing period, participants looked at alcohol warning labels for $1.03 \mathrm{~s}(S D=0.89,7 \%)$. A drink type (alcohol, soda) $\times$ AOI (brand, health, rest) repeated measures ANOVA revealed significant main effects of drink type $(F(1,56)=63.97, p<.001$, $\left.\eta_{\mathrm{p}}^{2}=.53\right)$ and AOI $\left(F(2,112)=84.47, p<.001, \quad \eta_{\mathrm{p}}^{2}\right.$ $=.60)$ that were qualified by a significant interaction $\left(F(2,112)=71.09, p<.001, \eta_{\mathrm{p}}^{2}=.56\right)$. Post-hoc comparisons showed that participants spent less time viewing health information than brand information (alcohol $\mathrm{t}(58)=14.36, p<.001, d=1.87$; soda $\mathrm{t}(56)=$ $7.17, p<.001, d=0.95)$ and the rest of the packaging (alcohol $\mathrm{t}(58)=10.62, p<.001, d=1.38$; soda $\mathrm{t}(56)=$ $12.95, p<.001, d=1.71)$. Participants also looked longer at alcohol branding than the rest of the packaging, $\mathrm{t}(58)=6.73, p<.001, d=0.88$, but less long at soda branding than the rest of the packaging, $\mathrm{t}(56)=$ 2.21, $p=.03, d=0.29$. Participants attended more to alcohol than soda branding, $\mathrm{t}(56)=11.78, p<.001, d=$ 1.56 , and less to the rest of alcohol than soda packaging, $\mathrm{t}(56)=4.44, p<.001, d=0.59$, but spent similar amounts of time viewing health warnings on alcohol and soda products, $\mathrm{t}(56)=.91, p=.37, d=0.12$.

Table 1 Studies 1 and 2. Stimulus characteristics

\begin{tabular}{lllllll}
\hline & Alcohol $(n=20)$ & & \multicolumn{3}{l}{ Soda $(n=20)$} \\
\hline & Brand & Health & Rest & Brand & Health & Rest \\
Variable & $M(S D)$ & $M(S D)$ & $M(S D)$ & $M(S D)$ & $M(S D)$ & $M(S D)$ \\
Size (\% of total container) & $34.24(12.56)^{\mathrm{a}}$ & $4.25(3.38)^{\mathrm{b}}$ & $61.51(15.04)^{\mathrm{c}}$ & $25.10(10.90)^{\mathrm{d}}$ & $5.47(2.88)^{\mathrm{b}}$ & $69.42(12.21)^{\mathrm{c}}$ \\
Complexity (compression ratio) & $.22(.04)^{\mathrm{a}}$ & $.27(.06)^{\mathrm{b}}$ & $.10(.02)^{\mathrm{c}}$ & $.26(.03)^{\mathrm{d}}$ & $.22(.07)^{\mathrm{d}}$ & $.12(.02)^{\mathrm{e}}$ \\
Brightness (average luminosity) & $111.92(44.07)^{\mathrm{a}}$ & $105.78(53.48)^{\mathrm{a}}$ & $91.54(37.22)^{\mathrm{a}}$ & $128.21(36.87)^{\mathrm{a}}$ & $118.19(48.83)^{\mathrm{a}}$ & $107.45(38.19)^{\mathrm{a}}$ \\
Contrast (luminosity variance) & $59.07(11.71)^{\mathrm{a}}$ & $48.58(15.46)^{\mathrm{b}}$ & $54.22(12.33)^{\mathrm{a}}$ & $59.07(11.71)^{\mathrm{a}}$ & $46.79(11.92)^{\mathrm{b}}$ & $52.70(13.05)^{\mathrm{a}}$ \\
\hline
\end{tabular}

Note: Comparisons are between means in the same row. Different superscripts indicate a significant difference between means $(p<.05)$ 


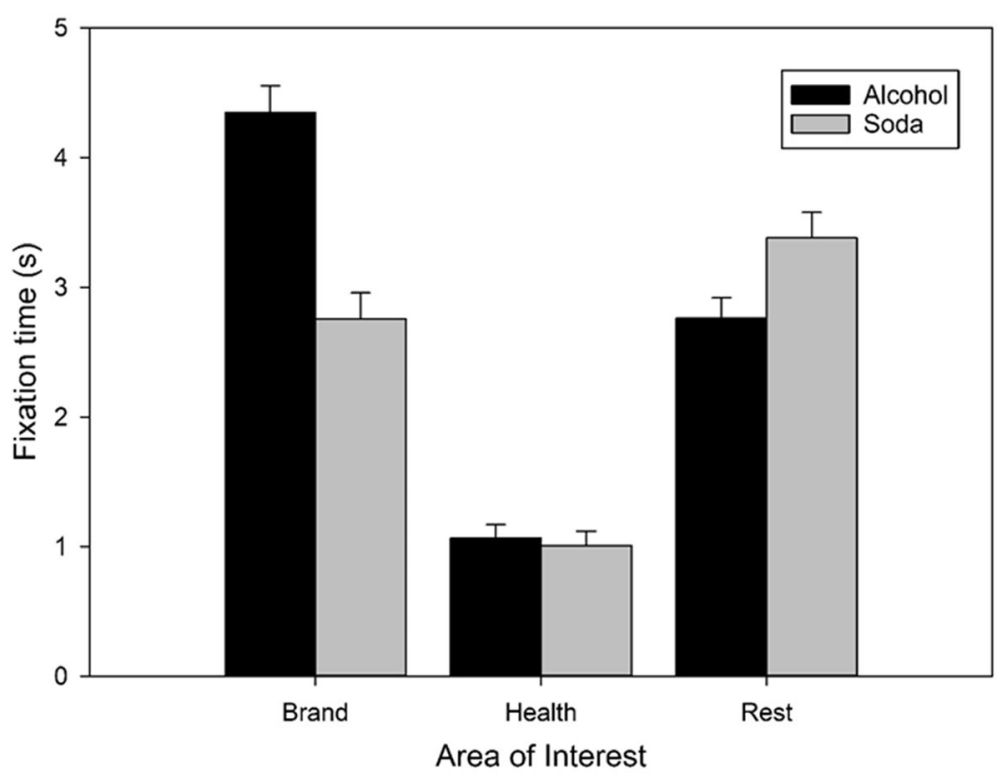

Fig. 1 Visual attention to the different areas of interest (Brand, Health, Rest) on alcohol and soda packaging. Bars represent raw mean fixation time (s) averaged out across trials. Error bars indicate SEM

\section{Stimulus characteristics}

The multilevel models revealed that the visual characteristics of branding and warning labels significantly affected attention. Alcohol warning labels were attended to longer when they were larger in size and less complex (see Additional file 1 for discussion).

\section{Individual differences}

Model 2 revealed a significant motivation to reduce drinking $\times$ AOI brand (vs health and rest) $\times$ picture type interaction (see Table 2). Motivation to reduce drinking was negatively associated with attention to branding on alcohol packaging. There was also a significant motivation to reduce drinking $\times \mathrm{AOI}$ health (vs brand and rest) $\times$ picture type interaction: motivation to reduce drinking was negatively associated with attention to health warnings on alcohol packaging. Taken together, these results indicate that participants high in motivation to reduce drinking paid less attention to alcohol branding and health warnings and more attention to the rest of the packaging. Recent alcohol consumption and AUDIT scores were not significant predictors of attention. There was a significant association between dietary restraint and attention to branding, which is discussed in Additional file 2.

\section{Study 2}

In study 2, we investigated the causal relationship between motivation to reduce drinking and attention allocation to branding/health warnings. First, to manipulate motivation to reduce drinking participants received a brief intervention regarding their drinking, or a control intervention. As the brief intervention predominantly targets people who drink in excess of the UK drinking guidelines, we recruited heavy drinkers. After the intervention, we measured attention to alcohol packaging. We hypothesized that participants would pay more attention to warning labels (and less to branding) after the alcohol intervention than the control intervention. Second, we manipulated attention to alcohol packaging so that participants either had to attend to warning labels or brand information. We used drinking intentions as the outcome measure, because they predict consumption [27] and are affected by changes in motivation to reduce drinking [28]. We hypothesized that participants who attended to health warnings would intend to drink less in the subsequent week than those who attended to branding.

\section{Method \\ Participants}

120 participants (65\% female) were recruited via online advertisements circulated among students and staff at the University of Liverpool (see Table 3). They were eligible for participation if they were aged over 18 , did not wear glasses and consumed more alcohol than the recommended UK guidelines (14 units/week for females, 21 units/week for males). ${ }^{2}$ There was no formal screening in place to check whether participants fulfilled these criteria prior to taking part, but the eligibility criteria were emphasized at multiple times prior to the start of the lab session. The study received ethical approval from the University of Liverpool Research Ethics Committee. 
Table 2 Study 1. Multilevel regression model including stimulus-level and participant-level predictors. Area of Interest (AOl; Brand, health, rest, dummy coded with rest as reference category), brightness, contrast, complexity, and size were level 1 (AOI-level) predictors. Picture type (Alcohol, soda, dummy coded with soda as reference category) and presentation order were level 2 (Picture level) predictors. AUDIT scores, recent alcohol consumption, motivation to reduce drinking and dietary restraint were level 3 (Participant level) predictors. All predictors were included as individual main effects and in all possible two-way and three-way interactions with picture type and $\mathrm{AOI}$

\begin{tabular}{|c|c|c|c|c|c|c|}
\hline \multirow[t]{4}{*}{ Variable } & \multicolumn{6}{|c|}{ Model 2 (stimulus-level and participant-level predictors) } \\
\hline & \multirow[b]{2}{*}{ Main effect } & \multicolumn{3}{|c|}{ Two-way interactions } & \multicolumn{2}{|c|}{ Three-way interactions. } \\
\hline & & $\times$ Picture type & $\times \mathrm{AOI}$ brand & $\times$ AOI health & $\begin{array}{l}\times \text { AOI brand } \\
\times \text { Picture type }\end{array}$ & $\begin{array}{l}\times \text { AOI health } \\
\times \text { Picture type }\end{array}$ \\
\hline & $b(S E)$ & $b(S E)$ & $b(S E)$ & $b(S E)$ & $b(S E)$ & $b(S E)$ \\
\hline Intercept & $3.22(0.84)$ & - & - & - & - & - \\
\hline AOl brand & $-3.73(1.20)^{* *}$ & $0.88(1.72)$ & - & - & - & - \\
\hline AOI health & $-2.95(0.97)^{* *}$ & $0.18(1.29)$ & - & - & - & - \\
\hline Picture type & $-0.61(1.09)$ & - & $0.88(1.72)$ & $0.18(1.29)$ & - & - \\
\hline Order & $0.01(0.01)$ & $-0.01(0.01)^{*}$ & $0.00(0.01)$ & $-0.003(0.01)$ & $0.01(0.01)$ & $0.01(0.01)$ \\
\hline Brightness & $-0.001(0.002)$ & $-0.001(0.003)$ & $0.002(0.003)$ & $0.001(0.003)$ & $0.01(0.01)$ & $0.002(0.004)$ \\
\hline Contrast & $-0.01(0.01)^{*}$ & $0.01(0.01)$ & $0.01(0.01)$ & $0.01(0.01)$ & $-0.01(0.01)$ & $0.01(0.01)$ \\
\hline Complexity & $11.12(4.18)^{* *}$ & $-1.90(5.98)$ & $-8.624(4.83)^{+}$ & $-10.46(4.27)^{*}$ & $2.41(6.62)$ & $-0.76(6.13)$ \\
\hline Size & $-0.01(0.01)$ & $0.01(0.01)$ & $0.02(0.01)^{*}$ & $0.08(0.03)^{*}$ & $0.02(0.04)$ & $-0.02(0.01)^{+}$ \\
\hline AUDIT & $-0.004(0.02)$ & $0.01(0.02)$ & $0.03(0.02)$ & $0.004(0.02)$ & $-0.04(0.03)$ & $-0.004(0.03)$ \\
\hline $\begin{array}{l}\text { Alcohol consumption } \\
\text { (last } 14 \text { days) }\end{array}$ & $0.002(0.01)$ & $-0.004(0.01)$ & $-0.002(0.01)$ & $-0.01(0.01)$ & $0.003(0.01)$ & $0.01(0.01)$ \\
\hline $\begin{array}{l}\text { Motivation to } \\
\text { reduce drinking }\end{array}$ & $-0.04(0.03)^{+}$ & $0.08(0.04)^{* *}$ & $0.01(0.03)$ & $0.05(0.03)^{+}$ & $-0.08(0.04)^{* *}$ & $-0.09(0.04)^{*}$ \\
\hline Dietary restraint & $-0.02(0.01)^{*}$ & $-0.02(0.01)$ & $0.02(0.01)^{*}$ & $0.01(0.01)$ & $0.02(0.01)$ & $0.02(0.01)$ \\
\hline Random effects & Residual variance & & Proportion resi & /ariance explained & & \\
\hline Level 3 & $0.14(0.03)$ & & $1.46 \%$ & & & \\
\hline Level 2 & $3.18(0.06)$ & & $17.15 \%$ & & & \\
\hline Level 1 & $0(0)$ & & - & & & \\
\hline$x^{2}(24)$ & $894.27^{* * *}$ & & & & & \\
\hline
\end{tabular}

Materials

Stimuli We used the same stimuli and questionnaires as in study 1 . Because the contemplation ladder was administered after the manipulation, baseline motivation to reduce drinking was defined as the average of the TRI restraint scale and RTCQ contemplation and action subscales, which were strongly correlated $(r=.52-.68, p \mathrm{~s}<.001)$.

Drinking intentions To measure drinking intentions, participants were asked how many pints of cider/beer,

Table 3 Study 2. Participant characteristics for each advice condition (alcohol, control) and exposure condition (brand, health)

\begin{tabular}{|c|c|c|c|c|}
\hline & \multicolumn{2}{|l|}{ Alcohol advice $(n=60)$} & \multicolumn{2}{|l|}{ Control advice $(n=60)$} \\
\hline & Brand exposure $(n=30)$ & Health exposure $(n=30)$ & Brand exposure $(n=30)$ & Health exposure $(n=30)$ \\
\hline Variable & $M(S D)$ & $M(S D)$ & $M(S D)$ & $M(S D)$ \\
\hline Gender (\% female) & $66.7 \%$ & $60 \%$ & $66.7 \%$ & $66.7 \%$ \\
\hline Age & $24.27(10.26)$ & $22.27(4.58)$ & $25.33(8.02)$ & $25.10(11.05)$ \\
\hline AUDIT $(a=.66)$ & $13.37(5.37)$ & $13.33(5.42)$ & $13.10(4.25)$ & $13.07(4.63)$ \\
\hline $\begin{array}{l}\text { Alcohol consumption } \\
\text { (last } 14 \text { days) }\end{array}$ & $48.13(26.48)$ & $51.23(23.54)$ & $47.00(17.37)$ & $48.27(23.05)$ \\
\hline $\begin{array}{l}\text { Baseline motivation to } \\
\text { reduce drinking }(a=.81)\end{array}$ & $1.61(3.64)^{a}$ & $2.90(3.92)^{a}$ & $4.51(2.95)^{b}$ & $2.64(3.55)^{a}$ \\
\hline DEBQ Restraint $(a=.92)$ & $34.73(8.08)$ & $35.30(10.48)$ & $34.47(8.93)$ & $34.53(10.92)$ \\
\hline
\end{tabular}


large glasses of wine, and shots of hard liquor they intended to drink in the next week [29]. Their responses were combined into a single measure of intended consumption in UK units. Binge drinking intentions were measured with three 9-point Likert scales (e.g., "Do you plan to binge-drink in the next week?" [30]). The scores were averaged into a single binge drinking measure $(\alpha=.97)$.

Viewing task The eye-tracker task was the same as in study 1 , with the exception that participants only viewed 30 containers during the viewing phase ( 15 alcohol, 15 soda) and 12 containers in the recognition phase.

Screening and intervention programme for sensible drinking (SIPS) brief advice tool [31] and control Participants were informed about their AUDIT scores and alcohol consumption, and the associated health risks, before receiving advice about population norms and the benefits of cutting down, followed by individualised tips to reduce their drinking. For the control condition, participants received brief advice on study habits. The advice closely followed the SIPS procedure, providing participants with information about different ways to study and their associated benefits and tailored tips to improve their own study habits (see Additional file 3).

Manipulation of attention task Participants were informed that important information for the subsequent memory test would be highlighted. They viewed the back and front labels of 15 alcoholic drinks containers with a bright yellow border around either the warning label or the brand information. To manipulate attention, in the health exposure condition, the majority of the labels had a border around the warning label (13 labels, $86 \%$ ), whereas in the brand exposure condition, the border was around the brand information.

\section{Procedure}

After giving consent, participants filled out the alcohol diary, AUDIT, TRI, and RTCQ. Then, half of the participants received brief advice on sensible alcohol consumption (alcohol advice condition), whilst the other half received brief advice about study habits (control condition). Then, participants did the viewing task. They were asked to indicate their motivation to reduce drinking on the contemplation ladder before and after the task. After this, participants received the manipulation of attention task. Half of the participants in the alcohol advice and control condition were allocated to the brand exposure condition and the other half were allocated to the health exposure condition. Allocation to the advice conditions and attention conditions was randomized. Then, participants completed the drinking intentions questionnaire and the $\mathrm{DEBQ}$, followed by a bogus memory task to corroborate the stated aim of the manipulation of attention task. Finally, participants were thanked and debriefed. Participants received study credits or a $£ 5$ high street voucher.

\section{Data preparation and analyses}

We employed the same data preparation and analysis strategy for the viewing task as in study 1 . Trials in which participants spent less than $50 \%$ of the viewing time looking at the stimuli were removed due to inaccurate tracking (9\%). A model with the level 1 and level 2 predictors (Model 1) was compared with Model 2 , which also included condition (alcohol advice vs control), and baseline motivation to reduce drinking as participant-level predictors (level 3). A chi-squared test showed that Model 2 was a significantly better fit than Model $1\left(\chi^{2}(12)=31.72, p<.001\right)$, which indicates that the level 3 variables predicted fixation time above and beyond stimulus characteristics.

\section{Results \\ Baseline differences}

A 2 (advice condition: alcohol, control) $\times 2$ (exposure condition: brand, health) MANOVA with age, recent alcohol consumption, AUDIT scores and the baseline measure of motivation to reduce drinking as dependent variables revealed significant baseline differences between conditions. There were significant group differences in motivation to reduce drinking for the advice conditions $\left(F(1,116)=4.20, p=.04, \eta_{\mathrm{p}}^{2}=.04\right)$, which were qualified by a significant advice $\times$ exposure condition interaction on motivation to reduce drinking $(F(1,116)$ $\left.=5.99, p=.02, \eta_{\mathrm{p}}^{2}=.05\right)$. Post-hoc t-tests showed that participants in the control condition had a stronger baseline motivation to reduce drinking than participants in the alcohol advice condition, $t(118)=2.02, p=.046, d$ $=.37$. This difference between advice conditions was only significant among participants in the brand exposure condition, $t(58)=3.39, p=.001, d=.88$, and not among those in the health exposure condition, $t(58)$ $=.27, p=.79, d=.07$, see Table 3 . There were no significant baseline differences in age, recent alcohol consumption, and AUDIT scores (all $p \mathrm{~s}>.23$ ).

\section{Free viewing}

Manipulation check An independent samples $t$-test revealed no significant difference in contemplation ladder scores between the alcohol advice condition $(M=4.72$, $S D=2.82)$ and the control condition $(M=3.95, S D=$ 2.94), $t(118)=1.46, p=.15, d=.27$. Therefore, the SIPS manipulation did not increase motivation to reduce drinking. 
Effects of advice condition on free viewing (Fig. 2)

Over a $15 \mathrm{~s}$ viewing period, participants looked at alcohol warning labels for $1.20 \mathrm{~s}(S D=0.81,8 \%)$. There was a significant $\mathrm{AOI}$ brand $\times$ condition interaction, indicating that participants who received alcohol advice spent less time viewing brand information than those in the control condition (see Table 4). The non-significant AOI brand $\times$ picture type $\times$ condition interaction showed that the relation between condition and attention to branding did not depend on picture type (alcohol vs. soda). The AOI health $x$ condition and the AOI health $x$ picture type $\times$ condition interactions were nonsignificant. This indicates that participants who received alcohol advice did not compensate their reduced attention to branding by increasing attention to health warnings on alcohol or soda containers, but instead increased their attention to the rest of the packaging.

\section{Exposure task}

Manipulation check Participants in the brand attention condition fixated longer on brand $(M=2.41, S D=1.21)$ than health information $(M=1.05, S D=0.42)$ and participants in the health attention condition fixated longer on health $(\mathrm{M}=2.13, S D=1.05)$ than brand information ( $\mathrm{M}$ $\left.=.86, \quad S D=.53 ; \quad F(1,116)=133.24, \quad p<.001, \quad \eta_{\mathrm{p}}^{2}=.58\right)$. Therefore, the manipulation of attention was successful.

Effect of attention to brand and health information on drinking intentions A 2 (exposure; brand, health) by 2 (condition; alcohol advice, control) MANOVA with binge drinking intentions and intended consumption as the DVs showed that exposure did not significantly affect drinking intentions (Multivariate $F(2,115)=.47, p=.62$, $\eta_{\mathrm{p}}^{2}=.01$ ). Neither did condition (Multivariate $F(2,115)=$ $\left.1.94, p=.15, \eta_{\mathrm{p}}^{2}=.03\right)$, or the interaction between exposure and condition (Multivariate $F(2,115)=.64, p=.53$, $\left.\eta_{\mathrm{p}}^{2}=.01\right)$.

\section{General discussion}

In two studies, we investigated alcohol consumers' attention to warning labels on alcohol packaging, and how this is associated with individual differences in motivation to reduce drinking. The results showed that people paid minimal attention to warning labels on alcohol packaging ( $7-8 \%$ of total viewing time). In study 1 , we demonstrated that self-reported motivation to reduce drinking reduced attention to both branding and warning labels on alcohol packaging. Although we did not replicate this association in study 2 , we did demonstrate that a brief alcohol intervention reduced attention to branding, although this effect was not specific for alcohol packaging and the brief alcohol intervention did not influence participants' motivation to reduce drinking. Contrary to hypotheses, our experimental manipulation that encouraged participants to focus their attention on warning labels did not affect their drinking intentions for the subsequent week.

A possible explanation is that participants do not particularly notice warning labels, due to their current design [14, 32]. Our results show that alcohol warning labels on average take up less than $5 \%$ of the packaging

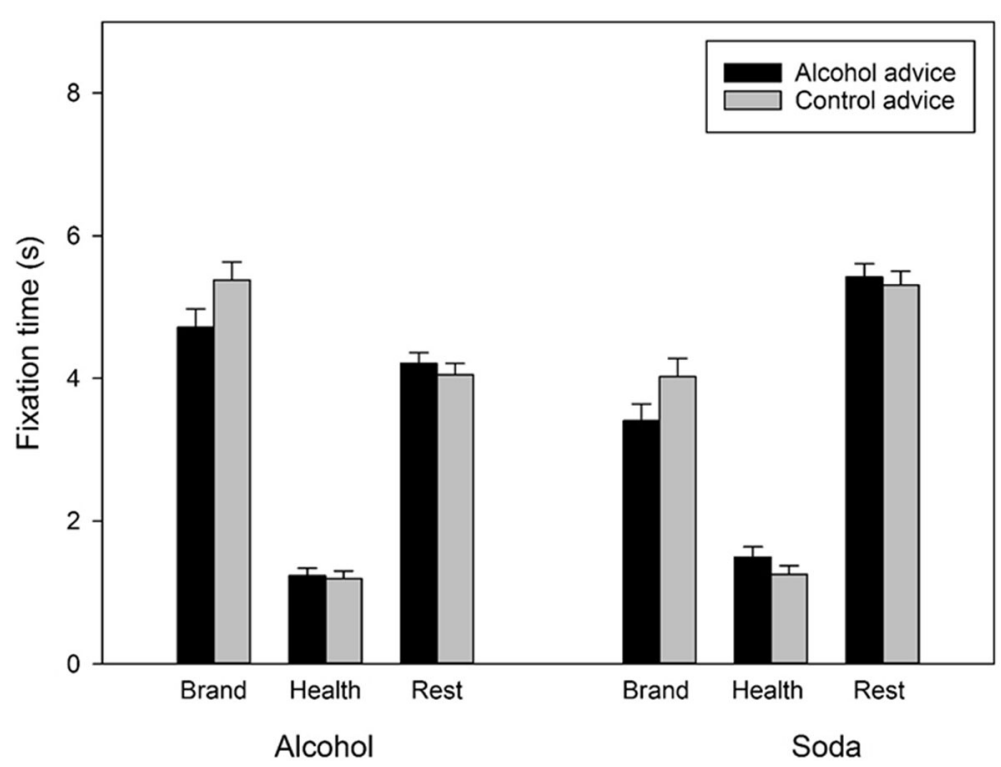

Fig. 2 Effect of condition (alcohol advice, control) on visual attention to AOls (brand, health, rest) on alcohol and soda packaging. Alcohol advice reduced attention to branding on alcohol and soda packaging. Bars represent raw mean fixation time (s) averaged out across trials. Error bars indicate SEM 
Table 4 Study 2. Multilevel regression model including stimulus-level and participant-level predictors. Area of Interest (AOl; Brand, health, rest, dummy coded with rest as reference category), brightness, contrast, complexity, and size were level 1 (AOI-level) predictors. Picture type (Alcohol, soda, dummy coded with soda as reference category) and presentation order were level 2 (Picture level) predictors. Advice condition (Alcohol, control, dummy coded with control as reference category) and baseline motivation to reduce drinking were level 3 (Participant level) predictors. All predictors were included as individual main effects and in all possible two-way and three-way interactions with picture type and $\mathrm{AOI}$

\begin{tabular}{|c|c|c|c|c|c|c|}
\hline \multirow[t]{4}{*}{ Variable } & \multicolumn{6}{|c|}{ Model 2 (stimulus-level and participant-level predictors) } \\
\hline & \multirow{3}{*}{$\begin{array}{l}\text { Main effect } \\
b(S E)\end{array}$} & \multicolumn{3}{|c|}{ Two-way interactions } & \multicolumn{2}{|l|}{ Three-way interactions. } \\
\hline & & $\mathrm{x}$ picture type & $\times \mathrm{AOI}$ brand & x AOI health & $\mathrm{x}$ AOI brand $\mathrm{x}$ picture type & $\mathrm{x}$ AOI health $\mathrm{x}$ picture type \\
\hline & & $b(S E)$ & $b(S E)$ & $b(S E)$ & $b(S E)$ & $b(S E)$ \\
\hline Intercept & $1.78(1.45)$ & - & - & - & - & - \\
\hline AOI brand & $-0.26(2.14)$ & $-22.46(3.04)^{* * *}$ & - & - & - & - \\
\hline AOI health & $-0.54(1.72)$ & $-8.46(2.23)^{* * *}$ & - & - & - & - \\
\hline Picture type & $8.46(1.93)^{* * *}$ & - & $22.46(3.04)^{* * *}$ & $-8.46(2.23)^{* * *}$ & - & - \\
\hline Order & $-0.01(0.01)$ & $0.02(0.02)$ & $-0.02(0.02)$ & $0.01(0.02)$ & $-0.002(0.02)$ & $-0.01(0.02)$ \\
\hline Brightness & $0.005(0.003)+$ & $-0.03(0.01)^{* * *}$ & $-0.01(0.01)$ & $-0.01(0.01)$ & $0.10(0.01)^{* * *}$ & $0.04(0.01)^{* * *}$ \\
\hline Contrast & $-0.01(0.01)$ & $-0.15(0.02)^{* * *}$ & $0.003(0.01)$ & $0.01(0.01)$ & $0.16(0.02)^{* * *}$ & $0.15(0.02)^{* * *}$ \\
\hline Complexity & $10.98(7.94)$ & $23.85(11.08)^{*}$ & $-4.14(9.06)$ & $-10.41(8.20)$ & $-18.89(12.32)$ & $-30.03(11.36)^{* *}$ \\
\hline Size & $0.03(0.01)^{* *}$ & $0.01(0.01)$ & $0.04(0.02)^{*}$ & $-0.02(0.06)$ & $0.14(0.03)^{* * *}$ & $0.20(0.07)^{* *}$ \\
\hline Advice condition & $0.03(0.27)$ & $0.37(0.32)$ & $-0.69(0.29)^{*}$ & $0.11(0.29)$ & $-0.45(0.40)$ & $-0.51(0.40)$ \\
\hline $\begin{array}{l}\text { Baseline motivation } \\
\text { to reduce drinking }\end{array}$ & $-0.01(0.04)$ & $0.04(0.04)$ & $-0.02(0.04)$ & $0.03(0.04)$ & $-0.07(0.06)$ & $-0.06(0.06)$ \\
\hline Random effects & \multicolumn{2}{|c|}{ Residual variance } & \multicolumn{4}{|c|}{ Proportion residual variance explained } \\
\hline Level 3 & \multicolumn{2}{|l|}{$0.55(0.12)$} & \multicolumn{4}{|l|}{$-29.67 \%$} \\
\hline Level 2 & \multicolumn{2}{|l|}{$4.29(0.26)$} & \multicolumn{4}{|l|}{$12.76 \%$} \\
\hline Level 1 & \multicolumn{2}{|l|}{$16.97(0.29)$} & \multicolumn{4}{|l|}{$35.1 \%$} \\
\hline$x^{2}(47)$ & \multicolumn{6}{|l|}{$31.72^{* *}$} \\
\hline
\end{tabular}

and that attention to warning labels is roughly proportional to their size. Additionally, our results suggest that large alcohol warning labels attracted more attention, but we did not experimentally test this. Research regarding tobacco labels supports this: larger labels increased message recall compared to smaller labels [33]. Another explanation is that participants do not see the current warning label as goal-relevant. This might be because it does not show the consequences of exceeding the recommended guidelines. Additionally, research suggests that "drink responsibly" messages (as included in the UK warning labels) are primarily used as a means to promote drinking [34-36] rather than raise awareness of the harmful consequences of alcohol consumption. Therefore, participants who are motivated to reduce drinking might view them as another part of the product branding, and subsequently avoid them. Indeed, some researchers argue that alcohol warning labels should be more like tobacco warnings and nutrition labels and provide clear information about alcohol-related risks and unambiguous behavioural recommendations in order to increase their effectiveness $[37,38]$.
Indeed, Al-hamdani and Smith [39] demonstrated that warning labels that provided unambiguous information about the effect of alcohol consumption on liver cancer made people perceive the product more negatively compared to non-labelled products. Similarly, warning labels about cancer also increased participants' intentions to reduce drinking $[40,41]$ and reduced participants' drinking speed [42], regardless of whether the warning label was text-only or included a picture of liver cancer. Another recent study showed that the inclusion of a selfaffirming implementation intention in addition to the standard UK warning label reduced alcohol consumption at one month follow-up [43]. Research on the effect of alcohol warning advertisements demonstrated that exposure to warnings affected urge to drink via increased negative affect in response to the warnings [44]. This suggests that alcohol warning labels might need to elicit negative emotions in order to reduce consumption. Future research should explore the effect of label design and content on attention. Increasing the visual salience of warning labels by using plain packaging $[9,10]$, graphic warnings [26] and front-of-pack labelling [45] 
might be more effective in attracting and maintaining attention, as shown in tobacco and food research.

These studies have some limitations. The viewing task in both studies comprised a $15 \mathrm{~s}$ viewing period for each beverage container and it was framed as a memory task to ensure that participants would attend to the packaging. The length of exposure and the instructions might have increased attention to areas that participants would normally ignore. Additionally, the alcohol advice manipulation did not increase motivation to reduce drinking, which means that the significant effect of advice condition cannot be interpreted as an effect of motivation to reduce drinking. Finally, when viewing multiple products at the same time, people pay more attention to the product they prefer [46]. We did not measure brand preferences in these studies, so it is possible that individual differences in brand preferences affected attention allocation to the branding/health warnings. However, we showed each product by itself, so there was no competition for attention between brands. Additionally, everyone had to view each product for exactly $15 \mathrm{~s}$, so participants could not decide to view the product for a shorter amount of time if they did not prefer the brand. Therefore, it is unlikely that individual differences in brand preferences had a substantial effect on our results. Our study also had strengths. We used existing alcohol containers with current UK health warnings and used multilevel modelling to control for differences in packaging design. We also used a combination of correlational and experimental designs to investigate the relation between motivation to reduce drinking and attention. Additionally, we allowed participants to manipulate their view of the beverage containers (front/ back, zoomed in/out) in any way they liked, which is more similar to real life viewing conditions. However, it should be noted that the manipulation of the containers was not the same as participants handling the container, which would have allowed them to tilt the container in order to better view vertical labels, for example.

\section{Conclusions}

To conclude, our studies show that people pay minimal attention to current UK warning labels on alcohol packaging. Motivation to reduce drinking decreases attention to branding, but does not increase attention to warning labels. Drinking intentions were not affected by attention to warning labels, even when participants had to attend to them. Changes in warning label design that make the label more visually salient and content are advised.

\section{Endnotes}

${ }^{1}$ One might argue that these labels do not warn against any adverse outcomes and should therefore not be called warning labels. In previous literature, these types of "drink responsibly" labels have been referred to as "warning labels" or "health warnings" [47]. For the sake of consistency, we will refer to the drinkaware labels as health warning labels in this manuscript.

${ }^{2}$ Recruitment for this study took place from May 2014 - September 2015, before the UK guidelines were revised (January 2016).

\section{Additional files}

Additional file 1: Study 1 - visual characteristics. A discussion of the association between stimulus size and complexity and visual attention to warning labels. (DOCX $12 \mathrm{~kb}$ )

Additional file 2: Study 1 - dietary restraint. A discussion of the association between dietary restraint and visual attention to branding. (DOCX $18 \mathrm{~kb}$ )

Additional file 3: Control intervention. Stimulus material used as part of the control invention regarding study habits. (PDF $410 \mathrm{~kb}$ )

\section{Abbreviations}

AOI: Area of Interest; AUDIT: Alcohol Use Disorders Identification Test; DEBQ: Dutch Eating Behaviour Questionnaire; RTCQ: Readiness to Change Questionnaire; SIPS: Screening and intervention program for sensible drinking; TRl: Temptation Restraint Inventory

\section{Acknowledgements}

N/A

\section{Funding}

The work was undertaken by the UK Centre for Tobacco and Alcohol Studies, a UKCRC Public Health Research Centre of Excellence. Funding from the Medical Research Council, British Heart Foundation, Cancer Research UK, Economic and Social Research Council and the National Institute for Health Research under the auspices of the UK Clinical Research Collaboration, is gratefully acknowledged. Funding bodies had no influence on the study design nor data collection, analysis and interpretation.

\section{Availability of data and material}

Data and materials will be made available upon request.

\section{Authors' contributions}

IK carried out the eye-tracking experiments, the analyses and drafted the manuscript. MF supervised the study conduct and helped draft the manuscript. Both authors were involved in the study design. Both authors read and approved the final manuscript.

\section{Competing interests}

The authors declare that they have no competing interests.

Consent for publication

Not applicable.

\section{Ethics approval and consent to participate}

The study received ethical approval from the University of Liverpool Research Ethics Committee. Reference: IPHS-1213-LB-024. All participants gave informed consent prior to taking part.

Received: 24 June 2016 Accepted: 19 January 2017

Published online: 26 January 2017

\section{References}

1. Public Health Responsibility Deal: Alcohol Pledges [https://responsibilitydeal. dh.gov.uk/alcohol-pledges/]. Accessed 23 Jan 2017.

2. Responsibility deal pledge on labelling [http://www.portmangroup.org.uk/ codes/alcohol-marketing/alcohol-labelling]. Accessed 23 Jan 2017. 
3. Stockley CS. The effectiveness of strategies such as health warning labels to reduce alcohol-related harms - an Australian perspective. Int J Drug Policy. 2001;12:153-66.

4. Stockwell T. A Review Of Research Into The Impacts Of Alcohol Warning Labels On Attitudes And Behaviour. Canada: Centre for Addictions Research of British Columbia; 2006.

5. Wilkinson C, Allsop S, Cail D, Chikritzhs T, Daube M, Kirby G, Mattick R. Report 1 Alcohol Warning Labels: Evidence of Effectiveness on Risky Alcohol Consumption and Short Term Outcomes. 2009.

6. Anderson P, Chisholm D, Fuhr DC. Effectiveness and cost-effectiveness of policies and programmes to reduce the harm caused by alcohol. Lancet. 2009;373:2234-46.

7. Knai C, Petticrew M, Durand MA, Eastmure E, Mays N. Are the Public Health Responsibility Deal alcohol pledges likely to improve public health? An evidence synthesis. Addiction. 2015;110:1232-46.

8. Thomsen SR, Fulton K. Adolescents' attention to responsibility messages in magazine alcohol advertisements: an eye-tracking approach. J Adolesc Heal. 2007:41:27-34.

9. Maynard OM, Munafò MR, Leonards U. Visual attention to health warnings on plain tobacco packaging in adolescent smokers and non-smokers. Addiction. 2013;108:413-9.

10. Munafò MR, Roberts N, Bauld L, Leonards U. Plain packaging increases visual attention to health warnings on cigarette packs in non-smokers and weekly smokers but not daily smokers. Addiction. 2011;106:1505-10.

11. Bialkova S, van Trijp HCM. An efficient methodology for assessing attention to and effect of nutrition information displayed front-of-pack. Food Qual Prefer. 2011;22:592-601.

12. Malouff J, Schutte N, Wiener K, Brancazio C, Fish D. Important characteristics of warning displays on alcohol containers. J Stud Alcohol. 1993;54:457-61.

13. Bialkova S, Grunert KG, Juhl HJ, Wasowicz-Kirylo G, Stysko-Kunkowska M, van Trijp $\mathrm{H}$. Attention mediates the effect of nutrition label information on consumers' choice. Evidence from a choice experiment involving eyetracking. Appetite. 2014;76:66-75.

14. Petticrew M, Douglas N, Knai C, Durand MA, Eastmure E, Mays N: Health information on alcoholic beverage containers: has the alcohol industry's pledge in England to improve labelling been met? Addiction 2015;111:51-55.

15. Saunders JB, Aasland OG, Babor TF, de la Fuente JR, Grant M. Development of the Alcohol Use Disorders Identification Test (AUDIT): WHO collaborative project on early detection of persons with harmful alcohol consumption-II. Addiction. 1993:88:791-804

16. de Meneses-Gaya C, Zuardi AW, Loureiro SR, Crippa JAS. Alcohol Use Disorders Identification Test (AUDIT): An updated systematic review of psychometric properties. Psychol Neurosci. 2009;2:83-97.

17. Sobell LC, Sobell MB. Timeline follow-back. In: Litten RZ, Allen JP, editors. Measuring alcohol consumption. Totowa, NJ: Humana Press; 1992. p. 41-72.

18. Sobell MB, Sobell LC, Klajner F, Pavan D, Basian E. The reliability of a timeline method for assessing normal drinker college students' recent drinking history: utility for alcohol research. Addict Behav. 1986;11:149-61.

19. Collins RL, Lapp WM. The Temptation and Restraint Inventory for measuring drinking restraint. Br J Addict. 1992;87:625-33.

20. Rollnick S, Heather N, Gold R, Hall W. Development of a short "readiness to change" questionnaire for use in brief, opportunistic interventions among excessive drinkers. Br J Addict. 1992:87:743-54.

21. LaBrie JW, Quinlan T, Schiffman JE, Earleywine ME. Performance of alcohol and safer sex change rulers compared with readiness to change questionnaires. Psychol Addict Behav. 2005;19:112-5.

22. van Strien T, Frijters JER, Bergers GPA, Defares PB. The Dutch Eating Behavior Questionnaire (DEBQ) for assessment of restrained, emotional, and external eating behavior. Int J Eat Disord. 1986;5:295-315.

23. Allison DB, Kalinsky LB, Gorman BS. A comparison of the psychometric properties of three measures of dietary restraint. Psychol Assess. 1992;4:391-8.

24. Laessle RG, Tuschl RJ, Kotthaus BC, Pirke KM. A comparison of the validity of three scales for the assessment of dietary restraint. J Abnorm Psychol. 1989; 98:504-7.

25. Forsythe A, Mulhern G, Sawey M. Confounds in pictorial sets: the role of complexity and familiarity in basic-level picture processing. Behav Res Methods. 2008;40:116-29.

26. Süssenbach $P$, Niemeier $S$, Glock $S$. Effects of and attention to graphic warning labels on cigarette packages. Psychol Health. 2013;28:1192-206.

27. Huchting K, Lac A, LaBrie JW. An application of the Theory of Planned Behavior to sorority alcohol consumption. Addict Behav. 2008;33:538-51.
28. Kaysen DL, Lee CM, Labrie JW, Tollison SJ. Readiness to change drinking behavior in female college students. J Stud Alcohol Drugs Suppl. 2009;16: 106-114.

29. Glock S, Krolak-Schwerdt S. Changing outcome expectancies, drinking intentions, and implicit attitudes toward alcohol: A comparison of positive expectancy-related and health-related alcohol warning labels. Appl Psychol Heal wellbeing. 2013;5:332-47.

30. Elliott MA, Ainsworth K. Predicting university undergraduates' binge-drinking behavior: A comparative test of the one- and two-component theories of planned behavior. Addict Behav. 2012;37:92-101.

31. Kaner E, Bland M, Coulton S, Dale V, Deluca P, Gilvarry E, Godfrey C, Myles J, Newbury-birch D, Oyefeso A, Parrott S, Perryman K, Shepherd J, Drummond C. Effectiveness of screening and brief alcohol intervention in primary care (SIPS trial): pragmatic cluster randomised controlled trial. BMJ. 2013;346:e8501.

32. Laughery KR, Young SL, Vaubel KP, Brelsford JW. The Noticeability of Warnings on Alcoholic Beverage Containers. J Public Policy Mark. 1993;12:38-56.

33. Truitt L, Hamilton WL, Johnston PR, Bacani CP, Crawford SO, Hozik L, Celebucki C. Recall of health warnings in smokeless tobacco ads. Tob Control. 2002;1 1:ii59-63.

34. Smith KC, Cukier S, Jernigan DH. Defining strategies for promoting product through "drink responsibly" messages in magazine ads for beer, spirits and alcopops. Drug Alcohol Depend. 2014;142:168-73.

35. Pettigrew S, Biagioni N, Daube M, Stafford J, Jones SC, Chikritzhs T. Reverse engineering a "responsible drinking" campaign to assess strategic intent. Addiction. 2016;111:1107-13.

36. Smith SW, Atkin CK, Roznowski J. Are Drink Responsibly alcohol campaigns strategically ambiguous? Health Commun. 2009;20:91-9.

37. Al-hamdani M. The case for stringent alcohol warning labels: lessons from the tobacco control experience. J Public Health Policy. 2014;35:65-74.

38. Martin-Moreno JM, Harris ME, Breda J, Møller L, Alfonso-Sanchez JL, Gorgojo L. Enhanced labelling on alcoholic drinks: reviewing the evidence to guide alcohol policy. Eur J Public Health. 2013;23:1082-7.

39. Al-hamdani M, Smith S. Alcohol warning label perceptions: Emerging evidence for alcohol policy. Can J Public Heal. 2015:106:e395-400.

40. Wigg S, Stafford LD. Health warnings on alcoholic beverages: Perceptions of the health risks and intentions towards alcohol consumption. PLoS One. 2016;11:e0153027

41. Pettigrew S, Jongenelis MI, Glance D, Chikritzhs T, Pratt IS, Slevin T, Liang W, Wakefield M. The effect of cancer warning statements on alcohol consumption intentions. Health Educ Res. 2016;31:60-9.

42. Stafford LD, Salmon J: Alcohol health warnings can influence the speed of consumption. J Public Health (Bangkok) 2016.

43. Armitage CJ, Arden MA. Enhancing the effectiveness of alcohol warning labels with a self-affirming implementation intention. Heal Psychol. 2016;35:1159-63.

44. Stautz K, Marteau TTM. Viewing alcohol warning advertising reduces urges to drink in young adults: an online experiment. BMC Public Health. 2016;16:530.

45. Graham DJ, Orquin JL, Visschers VHM. Eye tracking and nutrition label use: A review of the literature and recommendations for label enhancement. Food Policy. 2012;37:378-82.

46. di Pellegrino G, Magarelli S, Mengarelli F. Food pleasantness affects visual selective attention. Q J Exp Psychol (Hove). 2011;64:560-71.

47. Wilkinson C, Room R. Warnings on alcohol containers and advertisements: international experience and evidence on effects. Drug Alcohol Rev. 2009; 28:426-35.

\section{Submit your next manuscript to BioMed Central and we will help you at every step:}

- We accept pre-submission inquiries

- Our selector tool helps you to find the most relevant journal

- We provide round the clock customer support

- Convenient online submission

- Thorough peer review

- Inclusion in PubMed and all major indexing services

- Maximum visibility for your research

Submit your manuscript at www.biomedcentral.com/submit 